


\section{Democracia cultural y promesas de dinero. Políticas culturales y arm's length en la esfera anglosajona hoy (II) Jorge Fernández de León}

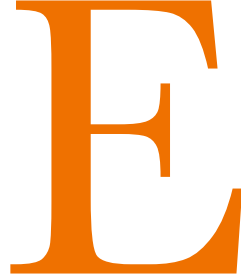

ntre el 22 y el 25 de septiembre de 2018 ha tenido lugar en Liverpool la tercera edición del festival TWT, ${ }^{1}$, The World Transformed (El mundo, transformado), un debate multitudinario organizado en paralelo a la Conferencia anual del Partido Laborista, en un momento de especial agitación política en la Gran Bretaña de este primer cuarto de siglo. El eje de este festival es la cultura en todas sus manifestaciones, Pero lo más significativo para nuestro repaso a la política cultural británica que viene, puede ser la inclusión en el programa de un denominado «Grupo de Lectura Eco-Corbynista» de una obra seminal de Raymond Williams «Hacia el año 2.000» (1983), que ya entonces proponía un análisis radicalmente nuevo de la acción política. Una propuesta de lectura crítica del mundo que, tras la ingente tarea de elaboración teórica del discurso cultural del intelectual galés, a partir de su trabajo de 1958 «Culture is ordinary» (la cultura es lo común, podríamos traducir es este caso), vuelve a tomar cuerpo en la discusión en torno a la cultura como uno de los tres campos -junto con la economía y la ecología- en torno a los que se forjan las respuestas políticas y ciudadanas desde la izquierda a la crisis global.
Este encuentro, así como el origen de este Festival son parte central de la estrategia de Momentum, grupo de acción política constituido para consolidar la posición del veterano dirigente Jeremy Corbyn al frente de los Laboristas, tras su triunfo en el Congreso de 2016. Momentum, ${ }^{2}$ una organización paralela al partido, cuenta ahora con más de 40.000 miembros y, a diferencia de cualquier otro movimiento reciente en la historia británica, ha hecho gala desde el principio de una especial preocupación por la cultura y por su papel transformador en la vida de la ciudadanía. Suya es la iniciativa para la presencia del líder laborista en el Festival de Glastonbury, donde Corbyn saludó a una efusiva audiencia juvenil, así como la menos feliz propuesta de continuidad de este éxito, el Festival conmemorativo Labour Day ${ }^{3}$ el pasado junio.

En torno a ellos se están uniendo diversas organizaciones como el Movimiento por la Democracia Cultural, ${ }^{4}$ el colectivo CulturaImporta ${ }^{5}$ (CultureMatters) y otros grupos de activismo que, por primera vez desde la segunda guerra mundial tratan de llevar la cultura a la agenda central de la política. Pero la dimensión que la política cultural y el estudio de sus procesos ha adquirido en Gran Bretaña tras la II Guerra Mundial no tiene probablemente paralelo en el mundo. 
Y ello en un marco casi omnicomprensivo en cuanto a sus márgenes y definición pero que, en palabras del citado $\mathrm{R}$. Williams, acabará casi siempre reducido al conflicto entre la voluntad conservadora de minimizar el papel del sector público en la cultura y el deseo de instituir un servicio público que abarque numerosas actividades humanas. Un mundo deseado cuyas instituciones no pueden entenderse sin «relacionarlas inmediatamente con el orden social en el que operan (...) pero la presión para reducir la participación del sector público en la cultura, en una nueva fase de competencia capitalista, seguía planteando la necesidad de dinero privado. Pronto una hoja de parra: El patrocinio. La deseada palabra, porque ¿no es el que patrocina un padrino? Así pues, no se trata de un vulgar empleo. Patrocinio. Ofertas y promesas. Promesas de dinero» (WILLIAMS 1983: 157, 159).

\section{El marco y la acción de las políticas culturales}

La política cultural es ampliamente reconocida como un arma eficaz que los modelos de gobierno neoliberales utilizan, muchas veces de forma indiscriminada, para perpetuar los mecanismos de segregación, haciendo de la esfera cultural un espacio privatizado, articulado en torno a las necesidades de las grandes corporaciones del entretenimiento y los media, reduciendo los recursos institucionales e impidiendo el desarrollo de las estrategias de las organizaciones públicas en favor de políticas de acceso universal (BELFIORE and BENNET, 2010; HEWISON, 1995; HEDSMONDHALGH, 2015; JESSOP, 1998).

Pero en el mundo de la cultura occidental ello no ha ocurrido sin conflictos. A los períodos de gobiernos socialdemócratas en el entorno cultural anglosajón han sucedido largos años de dominio conservador, pero en ambos, pese a la voluntad de las miradas progresistas como las del propio R. Williams o las del amplio grupo de teóricos reunido en torno al Centro de Estudios Culturales de Birmingham, origen indiscutido como veremos de la disciplina hoy consolidada de los estudios culturales, parecen seguir triunfado los intereses de la industria del entretenimiento frente a los compromisos para consolidar cartas de derechos culturales universales. La tensión creciente entre esas políticas y las comunidades afectadas han ido generando condiciones para un nuevo entorno, difícilmente imaginable hace solo unos años.

No es sin duda materia abordable en este texto, por su dimensión y complejidad, la determinación detallada de a qué llamamos políticas culturales o de cuáles son los sectores que componen el conjunto de políticas específicas y de formas de acción política creadas a través de los diversos programas prácticos y modelos organizativos que las articulan. A efectos de clarificación, seguimos, para determinar el marco conceptual que abarca nuestra mirada al caso británico, los trabajos del professor Clive Gray (2010, 2012) en los que se detallan esos marcos en campos como el desarrollo comunitario, la sostenibilidad, el patrimonio, la diversidad cultural, los estilos de vida, las industrias culturales y las industrias del entretenimiento y la creatividad, el planeamiento cultural la interculturalidad, la multiculturalidad, la lectura, las artes visuales, los museos, los archivos, el turismo cultural, la ciudadanía cultural, la esfera pública de la cultura y sus conflictos, por citar los más destacados.

A los efectos de este trabajo incluiremos además en el concepto, siguiendo la clasificación de D. Hedmondshalgh (et al, 2015: 6-11) la marca país, considerada como la narración de los historia del país hacia en interior y exterior, desde los eventos globales a la creación y consolidación de las instituciones culturales nacionales; la protección del patrimonio intangible, asdemás del tangible, desde las ceremonias y rituales a las comidas locales; los distintos modos de apoyo a la producción, distribución y consumo cultural (aplicando para el caso el modelo ya comentado en el artículo anterior de Chartrand y McCaughey (1989); y el modelo de control, regulación y censura tanto en materia de prohibiciones explícitas como a la hora de establecer prioridades de gobierno.

Abarcando el conjunto de estas categorías, el caso británico añade a nuestro entender a la mirada general sobre las políticas del arm's length, esa singularidad sobre la que han basculado las acciones de los sucesivos Gobiernos del país tras la II Guerra Mundial: La coexistencia de un discurso liberal-conservador que ha configurado la acción de las grandes instituciones culturales del país, (desde los Consejos de las Artes al British Council, los museos y bibliotecas nacionales, etc.), un intento - con resultados desiguales- de los gobiernos Laboristas, desde Harold Wilson y su Ministra para las Artes Jennie Lee hasta las propuestas del Nuevo Laborismo y la Tercera Via de Blair, de transformar esos comportamientos y una línea de pensamiento progresista, articulada en buena parte en torno al movimiento de la Nueva Izquierda, que daría lugar, a principios de la década de los 60 del pasado siglo, al más relevante de los procesos de reflexion crítica en torno a las políticas del sector, los Estudios Culturales como disciplina global, pero que hasta muy recientemente había confinado sus acciones al ámbito de la agitación académica. Trataremos de resumir a continuación algunos de estos factores y su importancia. 
La política cultural

\section{es ampliamente reconocida}

$$
\text { como un arma eficaz }
$$

que los modelos de gobierno

neoliberales utilizan [...] para

perpetuar los mecanismos

de segregación, haciendo

de la esfera cultural

un espacio privatizado.

\section{Un poco de historia (del siglo pasado, más o menos)}

La producción de textos propositivos de políticas y de análisis e interpretación de las mismas en el caso de Gran Bretaña tiene una amplísima bibliografía, tanto general como parcial (HEWISON, 1997, 1981, 1987, 1989, 1995, 2000, 2014; GRAY, 2000; HETHERINGTON, 2010; BELL and OAKLEY, 2014; O'BRIEN, 2014; HESMONDHALGH et al., 2015; MULCAHY, 2017). Buena parte de estos trabajos han sido realizados al calor de los distintos núcleos de investigación promovidos desde los departamentos de Estudios Culturales. De todos ellos, para seguir someramente el proceso histórico desde 1945 hasta hoy, y para cualquier exploración más profunda, recomendamos especialmente, por la vision general detalladísima que ofrece en sus siete volumenes sobre el tema, los trabajos sistemáticos de estudio del período del historiador y polemista Robert Hewison, ${ }^{6}$ a veces un académico clásico de los estudios culturales y otras un provocador, cuyas tesis radicales sobre la turistización de la identidad cultural (1989) se adelantaron décadas a las visiones críticas hoy comunes del asunto.

Pero a nuestros efectos, volveremos allí donde lo dejamos en el anterior artículo: A 1946, tras la conflagración mundial, y en el momento de la conversion del Consejo para la Promoción de la Música y las Artes (CEMA) en el Consejo de las Artes de Gran Bretaña (Arts Council of Great Britain, ACGB), el alma misma de la política del arm's length.

La iniciativa de John Maynard Keynes y su vision de la política cultural como una política de estado, recordemos que hizo posible la constitución de la primera agencia no directamente dependiente de la administración en el mundo. Una institución que el mismo dirigió hasta su prematura muerte y que nació impregnada del espíritu del Grupo de Bloosbury, del que era miembro activo y cuyas ideas sobre la posibilidad del Desarrollo de la creación exigían para los artistas una libertad de espíritu que «funcionaba mejor sin restricción política, social, financiera o estructural alguna» (UPCHURCH, 2004: 209).

Esta voluntad de superar un modelo burocrático de asignación de recursos para la cultura estaba muy presente en las iniciativas y estrategias del Grupo. No hay que olvidar que la filosofía política de Keynes nacía del juicio de que el capitalismo era un sistema con profundos desequilibrios y que era parte fundamental de los deberes del Estado moderno la redistribución de la riqueza económica de las naciones para mejorar la calidad de vida de las comunidades. Y las experiencias de la cultura controlada por el Estado habían dado entonces, en el primer tercio del siglo XX, numerosos ejemplos de imposición y control de las ideas, censura y violencia contra la creación en Alemania, Italia, Rusia o España, casos muy bien conocidos por la intelectualidad británica. Por eso fue importante para él, desde el principio del proceso, usar su influencia para conseguir que los recursos que se destinaban al Consejo no pasaran por otro Ministerio que no fuera el de Finanzas, sin intervención alguna de los de Educación o de Cultura.

Keynes logró que en los presupuestos del Gobierno británico para 1945 y 1946 se incluyera una partida de 235.00 libras esterlinas, destinada sobre todo al apoyo de las grandes instituciones culturales londinenses, como la Royal Opera House. Tras su muerte en 1946, el Gobierno mantuvo sus aportaciones anuales y las fue incrementando hasta llegar a la cifra de 820.000 libras en los presupuestos de 1955 y 1956, empujados de nuevo tras la llegada del historiador y divulgador del arte Kenneth Clark.

La actividad del Consejo de las Artes consistía principalmente en la distribución de recursos a fondo perdido para la producción y distribución de obras y proyectos artísticos, tras petición previa por parte de las organizaciones interesadas. Gracias a esas ayudas se pusieron en marcha giras y 
programas de difusión de las artes visuals y la ópera. Desde sus comienzos el Arts Council puso también en marcha una estrategia de adquisición de obras de arte (la Arts Council Collection), ${ }^{7}$ que fue alojando en distintos museos y colecciones públicas del país un fondo que hoy supera las 8000 piezas. La historia del Arts Council, dividido desde 1994 en tres distintos organismos independientes (Arts Council of England, Arts Council of Wales y Scottish Arts Council), no es, no obstante, el motivo principal de este artículo. Por su interés en todo caso puede seguirse, además de en la bibliografía general mencionada, en la detallada investigación de A. Sinclair (1995).

La política cultural británica, como la de cualquier país europeo, debe mucho más a la acción de los gobiernos locales, y a su insistencia en el mantenimiento de los servicios básicos de la cultura y a su capacidad resiliente en las distintas crisis, como veremos más adelante, que al devenir de esta gran institución simbólica. Porque serán las ciudades, especialmente las grandes urbes a través de los Distritos y Consejos Metropolitanos, las que llevarán adelante la mayoría de esas políticas. Y en paralelo a ellas, sin conseguir una capacidad de influencia relevante en las políticas laboristas, es necesario hacer mención del papel de la Nueva Izquierda, venida en muchos casos de la propia izquierda laborista, pero enriquecida por las idea de numerosos intelectuales comunistas, decepcionados con la actuación de la Unión Soviética, especialmente tras la invasion de Hungría. Una Nueva Izquierda que acabará instalada en el ámbito Universitario y que será el origen de la disciplina de los estudios culturales, como ya se ha comentado antes. Pero, por su relevancia en la construcción de la marca país, queremos detenernos, paralelamente a este relato del devenir del pensamiento crítico, en otros tres momentos de la acción declarative y ejecutiva de los Gobiernos que reflejan el devenir de las políticas públicas del país: El tiempo de Jenny Lee, el período Thatcher y la llegada de los gobiernos de la Tercera Vía. Y en algunos de los documentos que fundaron sus políticas.

\section{Jennie Lee. Los primeros pasos}

La presencia de Jenny Lee $^{8}$ en la vida política inglesa es larga y representativa del impulso de todo un grupo de militantes históricos del Partido Laborista, la mayoría varones y venidos como ella del mundo obrero. Hija de un minero galés, llega la la Universidad y entra en política nacional siendo elegida en 1929 como la Diputada más joven del Parlamento británico con 24 años, militando en el Partido Laborista Independiente en Escocia, ${ }^{9}$ una rama autónoma del
Partido Laborista que mantuvo su actividad hasta mediados de los 70. Las discrepancias entre su Partido y el Laborista británico respecto a la política del país confinaron su presencia pública al territorio escocés durante años, dedicando su tiempo a diversos trabajos, entre ellos las colaboraciones en periódicos y revistas de la izquierda inglesa.

En 1945 vuelve al Parlamento ya reintegrada en el Partido Laborista y en 1964, tras las elecciones generales que dan el triunfo a Harold Wilson, es nombrada Ministra para las Artes, puesto que ocupa durante un año para pasar después al frente del Ministerio de Educación y Ciencia y ser la encargada de poner en marcha la Universidad en las Ondas, la que luego será la Universidad Abierta (Open University). Para esta tarea presenta un Libro Blanco de la educación de adultos, en el que, bajo el título «Una Universidad en las Ondas» subrayaba la calidad necesaria de sus contenidos señalando que no podía haber duda de que sus futuros estudiantes deberían recibir la misma calidad de enseñanza que los de las universidades presenciales, si se quería que el Proyecto no fuera un fracaso. Esta segunda experiencia la pondrá en contacto con el trabajo y las ideas de los muchos colaboradores teóricos de la Asociación para la Educación Obrera (WEA), una iniciativa sindical y política muy enraizada entre las clases trabajadoras de las ciudades industriales británicas, Asociación en cuyo seno se formó y trabajó durante mucho tiempo Raymond Williams. ${ }^{10}$

En el corto período de tiempo de su mandato al frente del recién creado Ministerio de las Artes, tuvo tiempo para lanzar el documento que aún hoy, 53 años después, sigue siendo materia de referencia y debate en los sucesivos materiales que sobre la política cultural inglesa vienen elaborándose, desde el Informe Warwick ${ }^{11}$ (2015) al reciente Hacia la Democracia Cultural. Promoviendo capacidades culturales para toda la gente ${ }^{12}$ (2018), del prestigioso King's College. Se trata del Libro Blanco de política cultural A policy for the Arts. The first Steps ${ }^{13}$ en el que en 1965 plantea, tras un detallado estudio de los servicios e iniciativas culturales públicas y privadas en Gran Bretaña, cuatro grandes lineas de objetivos que necesitarán desarrollar la oportuna acción gubernamental para su consecución: En primer lugar señala que la capacidad para desarrollar y sostener un alto nivel de logros artísticos es central para las políticas culturales, y para ello será necesario que los creadores cuenten con mayores recursos financieros para poder desarrollar sus inciativas, especialmente en los primeros años de su práctica artística; en segundo lugar anuncia la esperanza del Gobierno en el compromiso de un gran incremento de recursos destinados a la cultura por parte de las au- 
toridades locales y regionales, convencidos de que solamente así se podrán alcanzar los objetivos perseguidos; el Gobierno, además, percibe la necesidad de sostener y reforzar lo mejor de la creación y hacer esta excelencia asequible para la ciudadanía; por ultimo señala la necesidad de una mayor y más sistemática planificación y coordinación de recursos.

Ya en ese documento (pp. 17-18) se subraya uno de los conflictos que ha sido motivo de debate constante en la política laborista frente a la de los gobiernos conservadores en el último siglo: la dependencia de las políticas culturales de las decisiones del Ministerio del Tesoro, de la hacienda pública. Ello implicaba una decisión que aún hoy, tras la creación por el primer Gobierno de Tony Blair de un organismo complejo que gestiona la política pública de la cultura como es el Departamento de Cultura, Medios y Deporte DCMS, ahora Departamento de Política Digital, Cultura, Media y Deporte, dependiente directamente del la Primera Ministra) sigue tanto en el seno del Partido Conservador como en el nuevo Laborismo de Corbyn: ¿Como y para qué ha de financiarse la cultura? ${ }^{14}$

Era pues el Libro Blanco de Lee una afirmación de la voluntad de hacer de la política cultural una herramienta de transformación y cambio en la calidad de vida, así como un factor central de la construcción de una nueva identidad en la que la cultura actuara como un factor de igualación social, una escalera de acceso para «la demasiada gente trabajadora que ha sido condicionada por su educación y entorno a considerar lo mejor de la música, la pintura, la escultura y la literatura lejos de su alcance» (p. 5). Considera no obstante que «una nueva generación más segura de si misma que sus mayores...reclamará diversidad y color, informalidad y experimentación». Y que no hay motivo para que un producto cultural bien presentado sea privilegio de aquellos cuyas preocupaciones básicas sean la cantidad y el beneficio.

De hecho en el texto se hace detallada mención a un instrumento, los Centros Cívicos y los Centros de Arte, ya relevantes entonces (y sostenidos económicamente en su mayoría por los Ayuntamientos locales y Metropolitanos) como los lugares en los que «se demuestra ya que no son incompatibles un entorno agradable y un celoso cuidado por el amntenimiento de los más altos estándares. Centros que tienen éxito en su propuesta de entornos amigables para el encuentro, donde conviven tanto el entretenimiento ligero como los proyectos culturales, ayudan a romper el aislamiento que tanto los artistas como los públicos potenciales han sufrido en el pasado» (p. 5). En estos espacios va a tener lugar durante más de medio siglo la pequeña transformación coti- diana de la cultura comunitaria, un fenómeno al que ahora, en 2018, vuelven a prestar atención algunas organizaciones defensoras de la recuperación de las prácticas de democracia cultural que los Centros han venido manteniendo, a pesar de todo.

Por desgracia, aquella voluntad de Wilson y Lee de romper con la hegemonía de los intereses de las élites culturales metropolitanas, especialmente londinenses, no ha sido posible, como el estudio de GPS (2016) señala detalladamente: de las 702 organizaciones que en 2016 recibían subvenciones de los organismos estatales - por un valor total de 775 millones de libras esterlinas- 84 de ellas se repartían el 81\% del presupuesto. Y de estas la absoluta mayoría estaban en la capital. De un total de 17 infraestructuras culturales del Estado, 16 estaban en Londres y 245 organizaciones de la capital se llevaban el 72\% de esos 775 millones.

\section{Consenso sin conflicto: Un deseo duradero}

Pero, como a continuación veremos, esta vision de la política cultural, cuando los gobiernos la llevan a la práctica, no difiere mucho de la que posteriormente defenderán los conservadores en el poder. Y, en las decisiones ejecutivas, presupuesto a presupuesto, va dirigiendo una cada vez mayor parte de los recursos a instituciones y programas cuya raiz está basada en buena parte en la apelación a la nostalgia y a la recreación del pasado. Un asunto que analistas como R. Hewison $(1989,1995)$ consideran parte de una gran política de consenso promovida por las formaciones políticas que se intercambian el Gobierno británico tras la II Guerra Mundial y que surge del declive del antiguo Imperio en el tablero internacional (pérdida de colonias, incluyendo la India, Birmania, Rodesia del Sur y otra docena de paises africanos, Chipre, Malta, etc., pérdida del control del Canal de Suez, conflicto norirlandés, islas del Caribe...) y de las dificultades para construir para sus propios habitantes una imagen sostenible de pais en un largo tiempo de declive. Y lo harán, todos los gobiernos, a través de la creación de los instrumentos más adecuados para aplicar la política del arm's length: Los Quangos.

Un quango (del inglés quasi-autonomous non-governmental organisation) es una mezcla de elementos propios de una organización del tercer sector con otros de instituciones públicas de los gobiernos. Instrumentos intermediarios puestos en marcha en numerosos paises para, en teoría, agilizar la realización de las políticas frente a la ineficacia burocrática de los mecanismos tradicionales de gobierno. En el caso británico esta definición se aplica tanto a Organizaciones públicas no 
gubernamentales ${ }^{15}$ (de las que cuentan con más de 750 en la actualidad, casi medio centenar dedicadas a asuntos culturales y aledaños), como a los Departamentos no ministeriales del Gobierno ${ }^{16}$ (algunos de los cuales también están relacionados con la cultura como la Comisión para las Organizaciones Benéficas de Inglaterra y Gales, la Forestry Commission - gestora de los bosques con gran incidencia en las políticas de patrimonio- o los Archivos Nacionales), y las Agencias Ejecutivas, ${ }^{17}$, entre las que se encuentran el Arts Council, La Fundación de la Lotería, principal patrocinadora de inversiones culturales ahora mismo en el país, el Instituto del Cine Británico (BFI), el Museo Británico, La Biblioteca Británica, la Comisión del Juego, la Galería National, la Tate y sus centros dependientes, el Museo Victoria y Alberto, El Museo de la Ciencia y otra docena de museos e instituciones que manejan la gran mayoría de los presupuestos culturales del Estado.

La creación del término, así como la defensa de su sentido, nos remite a unos viejos conocidos del anterior artículo: La Fundación Carnegie y uno de sus Presidentes más conocidos, Alan Pifer, que los definió así, quangos, (BARKER, 1982: 221) en un artículo sobre la independencia y control presupuestario de las organizaciones públicas que se integran al sector privado. El vínculo entre la vision privatizadora estadounidense y la prevención británica de la construcción del Estado Social, con recursos públicos de los Gobiernos frente al dominio de la iniciativa privada y de sus intereses, encuentra su solución consensuada en torno a estas figuras, en apariencia independientes, pero con una presencia en sus consejos ejecutivos de representación gubernamental suficiente como para garantizar un fuerte control de la dirección de los gastos, así como una concentración exagerada de los recursos en Londres y su entorno, como ya indicábamos señalan los informes Rebalancing our Cultural Capital ${ }^{18}$ (2013) y A Policy for the Arts and Culture in England. The Next Steps? ${ }^{19}$ (2016), de la consultora independiente GPS Culture. Ambos informes, por cierto, se consideran seguidores de los principos rectores de la memoria y objetivos del Libro Blanco de Lee.

La critica al funcionamiento de los quangos culturales, así como su denuncia como instrumentos al servicio de la mentira cultural asumida por los distintos gobiernos (Belfiore, 2010), tiene un excelente resumen en el libro de Hewison (1987) en el que, aplicando el análisis especialmente a los esfuerzos para obtener recursos privados de las instituciones culturales, ayunas de dinero público para mantenerse, describe la aparición de lo que denomina la Industria del Patrimonio, un campo que consume no solo gran parte de los recursos públicos y privados destinados a la cultura sino que nace con la vana esperanza de ocupar el espacio que la industria real deja en pleno declive de la economía del país. Por eso, afirma, «la industria del Patrimonio es un intento de disipar este clima de declive explotando el potencial económico de nuestra cultura, y encuentra un mercado listo para ello porque la percepción del declive incluye todo tipo de inseguridades y dudas, (que son más que simplemente económicas) lo que hace a sus productos especialmente atractivos y reafirmadores (...) El crecimiento de una cultura del patrimonio ha conducido no solo a una distorsión del pasado sino a la asfixia de la cultura del presente».

\section{Promesas de dinero (para otros) y toneladas de nostalgia}

Los quangos han servido también para alimentar la teoria del valor económico de la cultura como centro del argumento de defensa del destino de recursos al sector y en detrimento de los fondos destinados a los derechos de acceso o a las prácticas más comunitarias. Esa idea de la cultura como capital material y fuente de recursos económicos para las comunidades, seguida de la retirada de competencias y transferencias a los Gobiernos locales en la materia, se instauró definitivamente con la llegada primero de los gobiernos conservadores desde 1979 de Margaret Thatcher y fue muy corregida con el discurso de las Industrias Culturales y en seguida de las Industrias Creativas instaurados por el Nuevo Laborismo de Tony Blair.

Demostrar un sedicente antieuropeismo y recuperar las alianzas con la América de Reagan, privatizar el sector público, flexibilizar el mercado laboral y el despido, debilitar hasta la extenuación a los sindicatos y una desregulación general del sector financiero. Estos fueron los grandes argumentos de la Ministra más conocida del país. Y a la política cultural se le aplicaron las mismas recetas. Unas recetas que, aunque modificadas parcialmente por los gobiernos de la Tercera Vía, volvieron a estar activas en mayo de 2010, tras la llegada al poder de la coalición Conservadora-Liberal dirigida por David Cameron.

Y en este contexto, la avocación a la nostalgia, la centralidad de Londres y el papel del dinero se convirteron en el primer mandamiento de los gobiernos conservadores: el título del documento de estrategia para la década del Arts Council de 1985, La Gloria del Jardín. El Desarrollo de las Artes en Inglaterra, parafraseando el poema de Kipling que alienta a la superación personal y la pelea por la vida como respuestas en defensa del país (Our England is a garden and such gardens are not made/by singing "Oh, how beautiful!" and sitting in 


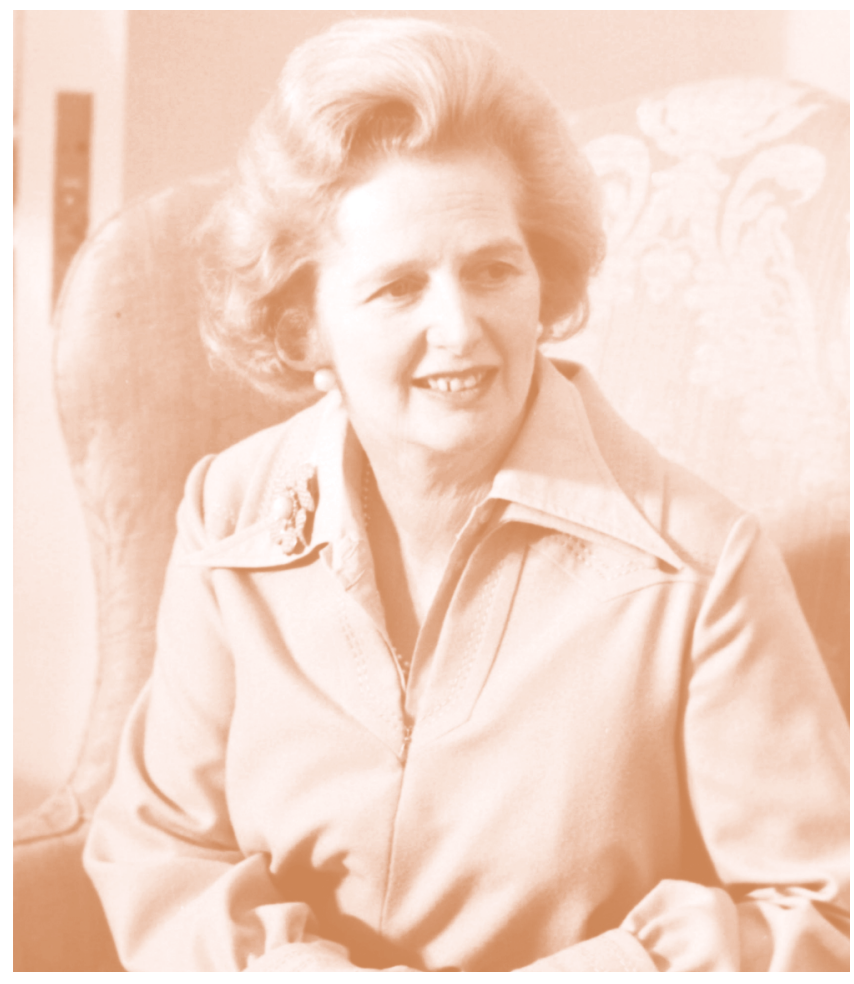

the shade; en traducción libérrima: Nuestra Inglaterra es un jardín y los jardines no están hechos/para cantar "jOh, que hermoso!" y a la sombra meternos) no deja lugar a dudas. Ni algunas de las palabras introductorias de su entonces Presidente, William Rees-Mogg, un empresario de prensa y periodista conservador que estuvo al frente de la institución desde 1982 hasta 1989 y bajo cuya dirección se redujeron a la mitad el número de instituciones receptoras de ayudas. «... La pérdida de los recursos artísticos para Londres costaría a la balanza de negocios tanto como la Perdida de una industria esencial. (...) el retorno económico de la inversión artística en libras parece multiplicar el de Fleet Street (la Bolsa)». Rees-Mogg aprovecha para deslizar la sempiternal queja de los informes y catálogos de intenciones del Arts Council: el de sobra conocido desequilibrio entre Londres y el resto del país en cuanto a la distribución de los recursos.

Y la situación no ha cambiado mucho desde entonces, pese a las numerosas modificaciones del estatuto y responsabilidades del Arts Council, especialmente tras la puesta en marcha en 1993 de la Loteria Nacional como principal gestor de recursos culturales del Gobierno, ${ }^{20}$ la puesta en marcha del Departamento de Cultura, Media y Deporte en 1997 con el primer Secretario de Estado de Blair, Chris Smith y la fusion de sus diez Consejos de las Artes regionales en el actual Arts Council England. Una lectura de su Plan Estratégico para 2010-2020, Great art and culture for everyone, nos presenta de nuevo el lenguaje rimbombante de la institución: «Nuestra ambición es la de ver la oferta cultural y artística de primera clase de Inglaterra disfrutada por tanta gente como sea posible (...) pero bajo todo esto (los cambios) nuestra misión sigue siendo la misma» (p. 63). Quizá la única novedad significativa respecto a esta posición, que indica algo respecto a la relevancia que vuelven a alcanzar en la agenda las políticas de la democracia cultural, venga dada por la publicación en 2016 del último Libro Blanco de la Cultura, ${ }^{21}$ por el DCMS. En él, las ideas recurrentes son una combinación entre la importancia del acceso universal y el modelo de cultura como negocio y marca pais.

El escritor Hanif Kureishi ${ }^{22}$ hacía para el diario the Guardian hace ocho años un resumen rápido de la vision de los creadores progresistas del período: «odiaba activamente la cultura, porque se daba cuenta de que era una forma de desacuerdo (...) Thatcher no comprendía el papel central de las artes en la vida británica. O lo buena que era Gran Bretaña produciendo libros, películas, teatro y música. Era una atomista social, además. No entendía el altruismo, la solidaridad y la identificación con los otros como una parte básica de la naturaleza humana (...) La solidaridad fue reemplazada por la sentimentalidad en la vida británica. «Mi hermosa lavandería» nació de los 70 por las políticas de identidad, el tema de los gays, de lo asiático, las ideas de raza, pero es también una sátira de la empresa thatcherita». La cultura era para Thatcher un modelo de coste-beneficio. Una idea que no se perdió del todo con la llegada del Nuevo Laborismo.

\section{La Tercera Vía, los municipios y la política cultural}

La llegada de Tony Blair al Gobierno trajo de nuevo al poder a los sucesores de Jenny Lee. Y lo hizo incorporando a su entorno más cercano, como Director de la Oficina estratégica del Primer Ministro, a Geoff Mulgan, ${ }^{23}$ un licenciado en telecomunicaciones, que, (según su ficha de Wikipedia) se presenta como ex-novicio de monje budista y conductor de furgoneta para el colectivo de músicos Red Wedge, con Paul Weller, Billy Bragg y Jimmy Somerville a la cabeza, uno de los grupos que luchaba contra la reelección de Thatcher. Mulgan, fundador del thinktank Demos, uno de los más influyentes centros de pensamiento tercera vía, próximo a Blair y actualmente Director Ejecutivo del influyente quango NESTA (National Endowment for Science Technology and the Arts), 
ha sido uno de los más influyentes arquitectos del discurso cultural del nuevo Laborismo.

Sus compromisos con la renovación y puesta al día de las ideas de Jenny Lee, una década antes de su salto al poder, coincidían entonces con el pensamiento de R. Williams y de la Nueva Izquierda, reclamando para la política cultural un papel transversal en la acción de los gobiernos. Ya en 1986, en pleno período de gobierno de Thatcher, junto con su entonces Jefe de la Unidad de estrategia Cultural en el Consejo del Gran Londres, Ken Worpole ${ }^{24}$ publicaba el libro-manifiesto Sábado noche o domingo mañana. De las artes a la industria. Nuevas formas de política cultural, que definía la estrategia cultural del Consejo (GLC), la corporación metropolitana dirigida por el ala más izquierdista del Partido Laborista. Ambos ocupaban en ese momento posiciones de responsabilidad en el diseño y desarrollo de la política cultural del que fue el verdadero opositor politico del gobierno conservador británico, el GLC, dirigido por el Alcalde Ken Livingston y disuelto tras grandes tensiones por la Primera Ministra para seguir acabando con los focos de resistencia politica interna nacional, a través de una Ley de 1985 que cercenaba las competencias de estos poderes metropolitanos y los hacía desaparecer.

Era a través de estos Consejos Metropolitanos, activos entonces en la mayoría de las áreas industriales de gran población de Gran Bretaña, como los Laboristas trataban de mantener políticas culturales de proximidad, cercanas a las propuestas formuladas por Lee en A Policy for the Arts... Y fueron los municipios los que, desde las ideas enunciadas en aquel Libro Blanco, diseñaron y experimentaron las acciones de cultura de proximidad que mantuvieron vivas las llamadas artes comunitarias, además de numerosas instituciones de servicio (bibliotecas, museos, etc). Desde muchos de estos gobiernos metropolitanos se experimentaron prácticas culturales de participación, creación y distribucion que ampliaron el espectro de la vida comunitaria a millones de ciudadanos, pese a las escasas o inexistentes ayudas estatales para este fin (BIANCHINI, 1986). Tras tres décadas largas, los problemas de la financiación en el territorio se siguen incrementando casi a diario, como puede comprobarse fácilmente. ${ }^{25}$

Por eso en la capital del país, el Alcalde del Gran Londres convirtió la institución en el escaparate de la política alternativa, mezclando una gran dosis de apoyo a las políticas de mercado junto con una gran presencia de las políticas comunitarias. El documento Sábado noche..., toma su título de una conocida película de Karel Reisz, uno de los más conocidos directores del del grupo Free Cinema, nacido a partir del manifiesto de 1956 Angry Young Men, en la que se cuenta la vida de un trabajador alienado cuya única práctica cultural es la salida alcoholica de los fines de semana. En el libro puede verse con claridad la influencia de la crítica cultural nacida de los nucleos de estudios culturales en torno al Centro de Estudios Culturales de Birmingham, al que luego se hará referencia. En el texto se critica cómo la politica cultural oficial refuerza los mecanismos de control sobre la clase trabajadora y propone un apoyo decidido a las formas de expresión comunitaria de la cultura colectiva, declarando que «los verdaderos disfrutes populares han sido ofrecidos y definidos en el ámbito del mercado, no por los elitistas museos, galerías y teatros financiados por el Estado. Las industrias culturales que producen las palabras, sonidos, imágenes y significados que nos rodean y bombardean han sido inmensamente dinámicas en estos años. La superestructura marxista, el reino de las ideas y las ideologías, se ha convertido en un motor principal para la base económica» (p. 10). Se define así un camino hacia la democracia cultural y el conjunto de este texto, declarativo y propositivo, no puede negar su deuda con la detallada lectura de Raymond Williams, especialmente de su Hacia el año 2000, incorporando además a las estrategias políticas del gobierno metropolitano todo lo relativo a los medios de comunicación (y aprovechando para poner al GLC como un caso de buena práctica en la innovación cultural). Seguía vivo el discurso de la nueva izquierda, que, como más tarde iba a ocurrir con el de las industrias creativas, haría fortuna en Universidades y thinktanks en medio mundo.

\section{Los estudios culturales, del aula a la calle}

Las versiones sobre el origen de los estudios culturales son diversas según sus investigadores y sus promotores. Así como nadie discute que Richard Hoggarth, ${ }^{26}$ Raymond Williams y E.P. Thompson ${ }^{27}$ son los tres nombres indispensables para la puesta en marcha del movimiento que hizo posible la constitución del Centro de Estudios Culturales Contemporáneos (CGCS) de Birmingham, son en cambio diferentes las percepciones de sus protagonistas e historiadores. Lo que es seguro es que los tres, de origen obrero, colaboraban en los movimientos políticos de la Nueva Izquierda británica, una tradición que dio lugar a toda una corriente de pensamiento que podríamos denominar marxismo británico; y que permanecieron vinculados siempre a partidos y sindicatos de izquierda, trabajaron para la ya mencionada Workers Educational Association (WEA), una organización de educación para trabajadores, de gran importancia desde comienzos de siglo, en la que después de la II Guerra Mundial (CEVASCO, 2013) y que sus compromisos con la idea de una educa- 
ción pública igualitaria que preparase las condiciones para el crecimiento de una cultura común y compartida que sustituyera la hegemonía de las élites que determinaban el valor de lo cultural por un dominio democrático para el que era necesario un cambio en el sistema productivo, que necesitaba de una clase trabajadora. La posición dominante en el Partido Laborista apostaba en cambio por la construcción de una nueva élite trabajadora que pudiera dirigir ese gran cambio.

Algunos investigadores (KAYE, 1995; DWORKIN, 1997) creen que el nacimiento del movimiento está ligado al grupo de intelectuales del Partido Comunista Británico que componía su Grupo de Historiadores (Christopher Hill, Eric Hobsbawn...), y que exploraban una nueva historiografia inclusiva al que se acercan y participan con mayor o menor compromiso partidario los tres fundadores. Muchos de los miembros de este influyente grupo, como tantos miembros de la intelligentsia británica de los años 50, rompen con el comunismo, decepcionados de la deriva autoritaria soviética, especialmente tras la invasión de Hungria por la URSS. Y que el libro de Thompson El Nacimiento de la Clase Obrera Británica es una piedra angular de lo que van a ser los estudios culturales. Y que ese vínculo se consolida con el nacimiento y la continuidad de la revista The New Left Review, que aún hoy trata de representar el pensamiento de una izquierda crítica con el funcionamiento del Partido Laborista. En todo caso, como señala otro de los miembros prominentes y director largo tiempo del CCCS, Stuart Hall, esa preocupación fue siempre también para con el marxismo mismo: «la Nueva Izquierda siempre recordó al marxismo como un problema, como un conflicto, como un peligro, no como una solución».

Williams, preocupado ya en 1986 por las tesis al respecto, señalaba en una conferencia pronunciada en Londres, al respecto del surgimiento de los estudios culturales que no

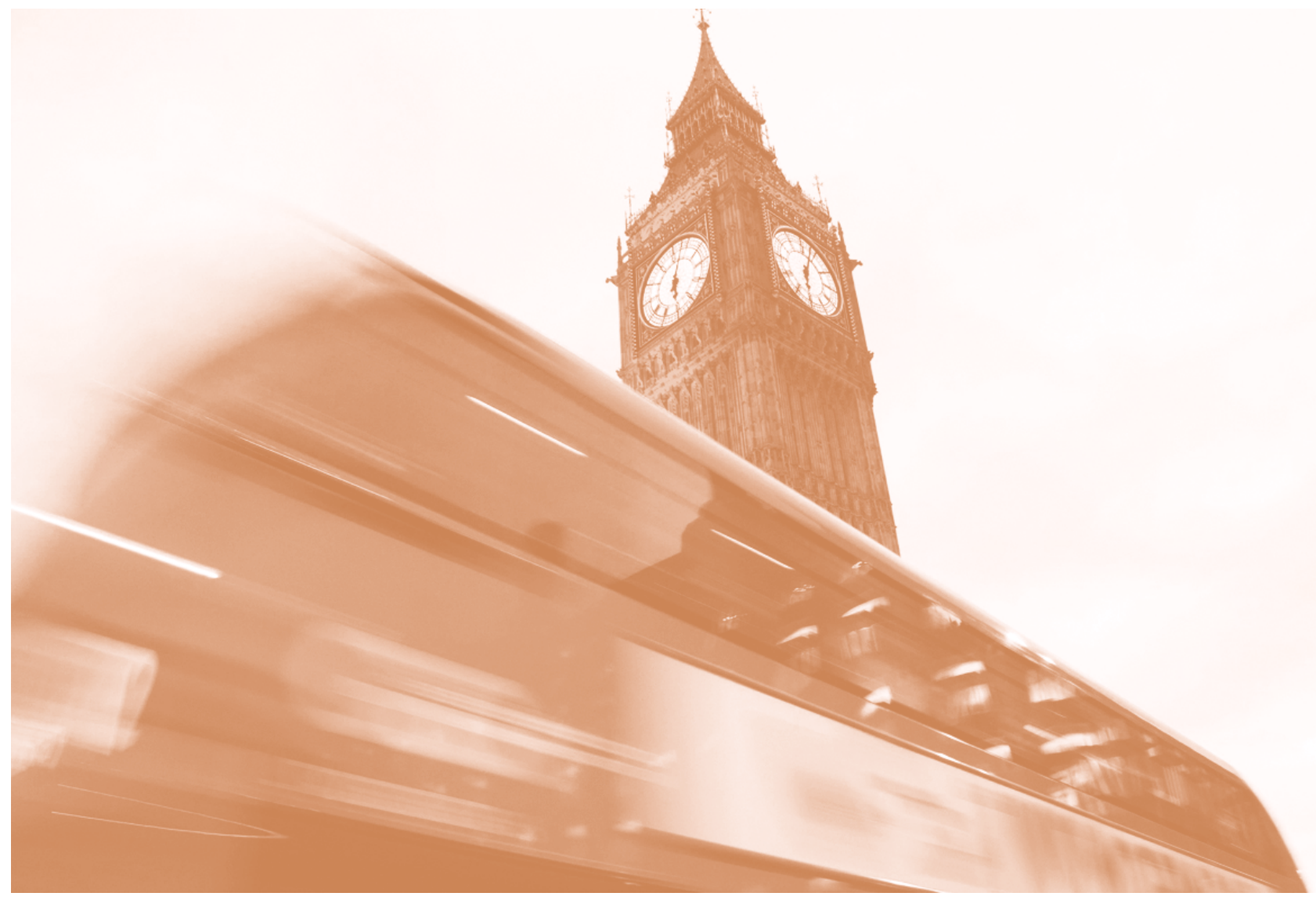


fueron los libros publicados en este o aquel año los que marcaron ese inicio, sino que «el cambio de perspectiva en la enseñanza del arte y la literatura, y su relación con la historia y la sociedad contemporáneas, comenzó con la Educación de Adultos y no en ningún otro lugar».

Sea como sea, este movimiento de análisis social, con la cultura como centro, ha logrado una extensión internacional en oriente y occidente, desde Estados Unidos a los grandes países asiáticos y africanos en los que el inglés (cuya historia como lengua de dominio es un factor esencial para entender también esa extensión) fue en algún momento lengua obligada o de prestigio. De esa corriente han nacido los estudios sobre culturas populares y juveniles que analizaron la marginación y los rituales de solidaridad de la clase trabajadora, los estudios de raza (HALL) y de género (McROBBIE), la incorporación de los fenómenos y las subculturas de la música popular, la moda, los peinados (HEBDIDGE) o la historia de los obreros (CLARKE), los estudios postcoloniales, la teoría y crítica de los medios de comunicación de masas. Historiadores culturales y sociales como Terry Eagleton (con sus dudas constantes), Tony Judt, Frederic Jameson, Judith Butler, George Yudice, Toby Miller, Gayatri C. Spivak, Jesús Martín Barbero, Beatriz Sarlo o Néstor García Canclini, por citar algunos nombres, participan de visiones críticas nacidas o compartidas con esta corriente de pensamiento, muy cuestionada hoy por el pensamiento venido de Francia (de Foucault a Badiou o Rancière) más preocupado por la teoría y alejado más y más de las ciencias sociales. Ese, en cualquier caso, es otro tema.

Hoy, como veremos más adelante, en la escena politíca e intelectual británica el impacto de estas ideas ha vuelto a encontrar un creciente espacio en la esfera pública, gracias a la aproximación entre los movimientos en favor de las artes comunitarias, muy arraigados en Gran Bretaña, y la política partidaria de nuevo cuño, simbolizada por el Movimiento para la Democracia Cultural y otras iniciativas similares.

\section{Llegan las industrias creativas}

La victoria del nuevo laborismo en las elecciones generales de 1997 en Gran Bretaña no seguiría sin embargo los pasos ni las prioridades y estrategias culturales de esta corriente de pensamiento. El ascenso de Mulgan al entorno del nuevo gobierno Laborista en 1997, junto con un grupo de asesores formados en el entorno de los estudios culturales (SCHLESINGER, 2007) no supondría el triunfo de las ideas que defendía en 1986 y si la constitución de un discurso que haría fortuna en el mundo desde entonces. Los sucesivos gobiernos de Blair abordaron la política cultural como una oportunidad de consolidar la idea de las Industrias Culturales y Creativas como uno de los motores de la economía del país, reconociendo el papel de la creatividad en el crecimiento y la producción de riqueza y la importancia crucial de la llamada economía del conocimiento.

Como analiza en detalle D. Hesmondhalgh (2015) la llegada de este gobierno, capaz de ganar sucesivamente tres convocatorias electorales (1997, 2001 y 2005) no supuso en absoluto la continuidad de las políticas conservadoras. De hecho, frente a la idea supuso cambios importantes respecto a las políticas educativas, incorporando al curriculum escolar el desarrollo de la creatividad al mismo nivel que la lectura y la matemática básica. Los museos públicos pasaron a ser gratuitos, se abrieron grandes equipamientos culturales como la nueva Tate o la colección Saatchi, lo que generó un incremento importante del consumo cultural en el país (principalmente en Londres de nuevo); se pusieron en marcha numerosos programas de integración positiva de las minorías a través de acciones en favour de la diversidad cultural, se buscó una mayor presencia de la cultura en las regiones y municipios y se multiplicó el discurso de la participación de las comunidades en las artes. Muchos cambios que incluso, en los discursos iniciales, parecían conducir a un nuevo replanteamiento de la democracia cultural, olvidada en los modestos programas de

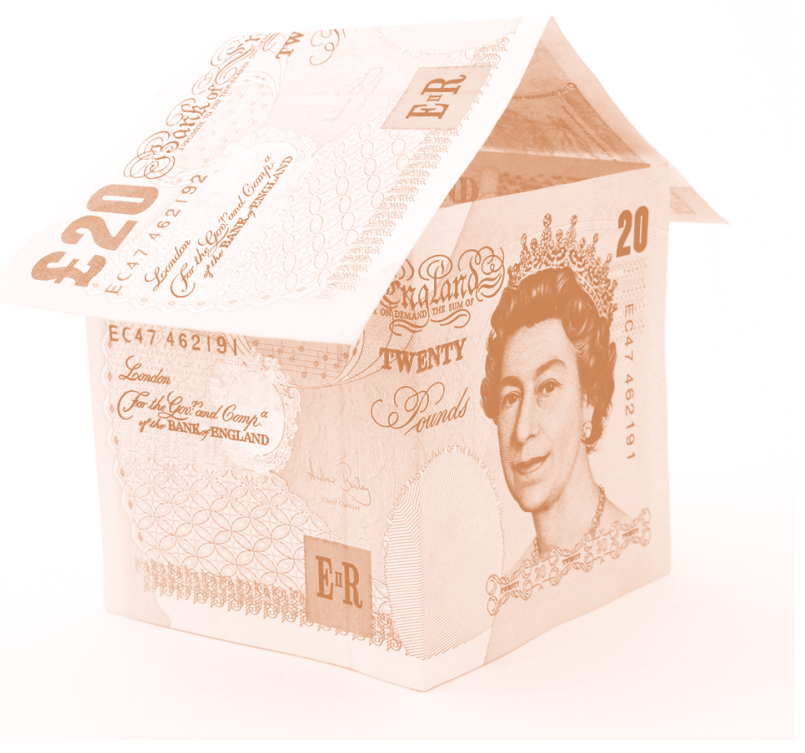


cultura comunitaria vinculados tanto a organizaciones del tercer sector como a centros cívicos y otras instituciones culturales públicas, dependientes de Ayuntamientos y regiones.

Parece claro que la estrategia de apoyo Laborista a las fuerzas del mercado como motores esenciales de la economía, la prioridad a la creación de empleo y el refuerzo de los vínculos con Estados Unidos, asi como la obsesión por el control del gasto público y en especial el destinado a ciertas políticas delestado de bienestar (desde la vivienda pública, los seguros de vida, la atención sanitaria y la educación superior), aunque correspondiera a un modelo económicamente schumpeteriano de microgobierno (HESMONDHALGH et al., 2014: 19-23) no destinó los recursos, como hubieran hecho los conservadores, a reducir impuestos, sino que «trata de usarlos para provocar una redistribución encubierta del gasto del bienestar hacia los muy pobres, a través de beneficios con destinatarios muy seleccionados por sus recursos».

La economía creativa sería no obstante el gran objetivo de los sucesivos gobiernos de Blair. Desde el Departamento de Cultural, Medios y Deporte (DCMS), Chris Smith, su primer responsable, pondrá en marcha un amplio programa de character socioeconómico, (HESMONDHALGH et al., 2015), apoyado en la experiencia y el conocimiento de diversos núcleos de pensamiento, desde los think tanks próximos al laborismo hasta diversos lideres del sector industrial y expertos asesores del Gobierno. Una economía competitiva, pensada para ocupar el lugar de las antiguas economías industriales en decadencia, que complementaba la consolidada industria del patrimonio y la incipiente industria tecnológica y se combinaba con ellas. En una conferencia en 2003, el propio Smith, describía el carácter y objetivos de esa economía creativa: «en 1998, como Secretario de Estado para la Cultura, los medios y el deporte, del nuevo Gobierno Laborista, publiqué un libro, Creative Britain. En él defendía que las artes eran para toda la gente, no solo para unos pocos privilegiados; y que las industrias creativas - que dependían para su éxito de la creatividad artística de los individuos- se habían movido desde los márgenes al centro de la economía de Gran Bretaña, con enormes beneficios para la salud social y económica de la nación. Llamaba a alimentar y celebrar el talento creativo para colocarlo en el corazón de la agenda política».

Quedaba pues instituida una política en la que la cultura pasaba a convertirse en un asunto central de la estrategia económica, desde sus detallados impactos en el empleo y la aportación al PIB británico hasta su capacidad como trasmisora de valores y conductora de estrategias via soft power.
Y aunque numerosos economistas y expertos han alertado sobre el efecto negativo de esta primacía del valor económico de la cultura - desde Throsby (2010) a Bakhshi y Cunningham (2016) - en el establecimiento del capital cultural mismo de las comunidades, hasta hoy el discurso dominante en los grandes partidos sigue aceptando que el sector cultural y creativo ha sido y seguirá siendo central en el proceso de recuperación económica británico tras la crisis y que deberá serlo en el tiempo post-brexit. El Informe Bazzalguette (2017) encargado por el DCMS continúa en la línea triunfalista cuando afirma que las industrias creativas aportaron el 5,3\% del PIB británico en 2015, creciendo un 34\% desde 2010, a más velocidad que ningún otro sector, y que a ese ritmo podrían crear por si solas más de un millón de empleos para 2030.

No cabe en cualquier caso duda alguna del éxito de la idea en el mundo. Tanto la Union Europea, como la UNES$\mathrm{CO}$ y Naciones Unidas en su conjunto, la OCDE y todo tipo de organismos internacionales y países se han sumado, en distinto grado y con diferentes dimensiones del sector, al discurso de las industrias creativas en los últimos quince años. El programa de ayudas culturales de la UE se denomina definitivamente Europa Creativa, tras todo un camino definitorio desde el Tratado de Lisboa del papel de las industrias culturales y creativas en el futuro de la economía europea (apoyado este camino en informes encargados, sistemáticamente, a la influyente consultora KEA, 2006, 2009, 2017.) Y en las previsiones de la Europa post 2020, las industrias creativas van a jugar un papel central de las estrategias de inversión de la UE. La UNCTAD/UNESCO lleva desde 2004 reuniendo datos y difundiendo programas e informes de economía creativa. ${ }^{28} \mathrm{Y}$ hasta la OCDE desarrolla su propia estrategia en el sector. ${ }^{29}$ Eso sin olvidar que China ${ }^{30}$ tiene su propia estrategia para las industrias creativas desde hace una década y que son mayoría los países que se afanan en desarrollarla con mayor o menor fortuna.

\section{El peso del presente y los debates en marcha}

Hemos tratado de vislumbrar como la decantación del peso del pensamiento crítico generado por los estudios culturales llegó también intensamente a algunos de los protagonistas de la elaboración teórica y la materialización de las políticas del Nuevo Laborismo (Chris Smith, Tessa Jowel, su sucesora al frente del DCMS, los ya citados Geoff Mulgan y Ken Worpole, Hasan Bakhshi, el director de investigación de NESTA, el actual quango de Mulgan...), protagonistas crecidos en ese entorno de los estudios culturales, teóricos 
incluso de la necesidad de la democracia cultural pero a la vez responsables visibles del gran cambio hacia la centralidad de las industrias creativas como eje y destinatario último de buena parte de los recursos culturales, en detrimento de otras posibles prioridades. Unas industrias que P. Schlesinger (2016) se atreve a calificar como la «invención de una economía global», tejida desde el Estado y acompañada por una cuidadosa orquestación de instituciones, medios, academia y negocios del entretenimiento; una operación que con los visos triunfalistas que acompañan a la última presentación de los datos, en apariencia independientes, de las industrias creativas, ${ }^{31}$ pareciera decir que ese triunfo no solo es inapelable, sino que el mundo entero está siguiendo sus pasos (asunto este al que en estas y otras páginas habrá que dedicar espacio y análisis futuro).

El análisis de Schlesinger, así como el de otros autores (RAUNIG, 2007; SCHLESINGER et al. 2015; BELFIORE, 2018), ahonda en las falacias de una estrategia que, diciendo ser de política cultural, responde principalmente al desarrollo en el gigantesco sector del entretenimiento de una de las fases actuales del capitalismo digital de plataformas (SRNICECK, 2016), basado en la falsa promesa de mayor libertad de elección, flexibilidad, transparencia y democratización del acceso, y ofreciendo en realidad precarización, eliminación de derechos laborales, oscuridad cuando no impunidad fiscal para los países... Esta fue la idea que el Nuevo Laborismo forjó y los Gobiernos conservadores mantuvieron y desarrollaron.

Pero en el panorama de la política y las ideas, como veíamos al principio del artículo, crecen en los últimos años nuevos movimientos para la recuperación de la democracia cultural como conductora central de las políticas públicas para la cultura. Iniciativas que recuperan la historia y trayectoria del Movimiento por las Artes Comunitarias (JEFFERS and MORIARTY, 2016), así como el debate en torno al papel de las políticas culturales en el establecimiento de una democracia real, frente al análisis (FROW, 1995; GRAY, 2010) que adscribe al esas políticas al campo de las fuerzas del poder, como un factor más de representación simbólica, sin impacto real en los cambios productivos y sin capacidad alguna para trasformar la vida de las comunidades. Los intentos del nuevo Director del Arts Council, anteriormente multipremiado y reconocido factotum de la Tate, Sir Nicholas Serota, para convertir su programa Creative People and Places $^{32}$ en un proyecto de democracia cultural parecen quedarse más en otro proyecto de democratización de la cultura, como Eleonora Belfiore señala en un reciente artículo (BELFIORE, 2018). Pero otras iniciativas, como las del ya citado Movimiento para la Democracia Cultu- ral, planteando una profunda reformulación de los sistemas de financiación de la cultura (estableciendo un impuesto sobre las transacciones artísticas), la creación de una nueva editora nacional pública multimedia y digital o un redimensionamiento de las organizaciones y poderes que gobiernan el mundo de la cultura británica, formulan de nuevo, en el espíritu más crítico de los Estudios Culturales, algunas de las cuestiones importantes respecto a la autoridad cultural, debatiendo el sentido y la oportunidad de seguir aceptando como buenos los discursos del gusto y la gran tradición europea, nacidos del pensamiento de la burguesía ilustrada de hace dos siglos.

Se recuperan en este contexto los escritos de otro seguidor de Williams, Owen Kelly, que hace tres décadas publicaba su Cultura y Democracia. Un manifiesto (1986) en el que el autor reivindicaba con precisión algunos de los caminos que la política ha de tomar, si quiere que la cultura cumpla un papel en la transformación de las vidas de quienes se acercan a ella. Romper la escala de valores, considerar que los derechos de acceso ${ }^{33}$ no pueden limitarse a los productos culturales sino a las herramientas que los hacen posibles. Estrategias de cambio frente a programas de uso, democracia cultural y promesas de dinero. El debate está vivo y ha vuelto a la luz de la calle, frente al poder definitorio del stablishment cultural, que domina los aparatos decisorios de los Estados y, convenientemente desde la sombra, define sus normas. ¿Habrá condiciones para el combate?

\section{Notas}

(1) https://www.telegraph.co.uk/music/concerts/ glastonbury-festival-2017-pictures/labour-leader-jeremy-corbyn-welcomed-stage-glastonbury-founder/(consultado el 01-10-2018)

(2) https:/ / peoplesmomentum.com/

(3) https://www.theguardian.com/politics/2018/ jun/ 17 /labour-live-festival-hailed-a-success-by-corbyn-party-despite-ridicule_(consultado el 01-10-2018)

${ }^{(4)}$ http://www.culturaldemocracy.uk/

(5) https://www.culturematters.org.uk/index.php

(6) Sobre R. Hewison, ver: https:/ / www.theguardian. com/books/2014/dec/12/cultural-capital-rise-fall-creative-britain-robert-hewison-review (consultado el 02-10-2018)

(7) Sobre la Arts Council Collection: http://www. artscouncilcollection.org.uk/ (consultado el 08-10-2018)

(8) http://www.open.ac.uk/researchprojects/historyofou/story/jennie-lee

(9) Sobre Jenny Lee y el ILP ver: http:/ /www.independentlabour.org.uk/main/history/ (consultado el 03-05-18). 
(10) Sobre la Workers Education Association y R. Williams: P. H. Stevens, (1985) Education culture and politics: the philosophy of education of Raymond Williams. Tesis doctoral. http://discovery.ucl.ac.uk/10018669/1/128120.pdf (consultado el 03-05-18). J. McIllroy and S. Westwood, (eds.) (1993). Raymond Williams in Adult Education, Leicester, National Institute of Adult Continuing Education, https://archive.org/details/ERIC_ED358300 (consultado el 03-05-18).

(11) Acceso al informe Warwick «Enriching Britain: Culture, Creativity and Growth» (2015) https://warwick. ac.uk/research/warwickcommission/futureculture/finalreport/warwick_commission_report_2015.pdf (consultado el 06-05-18).

(12) Acceso al informe «Towards Cultural Democracy» (2017): https://www.kcl.ac.uk/cultural/culturalenquiries/towards-cultural-democracy/towards-cultural-democracy-2017-kcl.pdf (consultado el 09-05-18).

(13) ribd//downloads/260115873-Jennie-Lee-A-Policy-for-the-Arts-1965.pdf

(14) Para seguir el último debate parlamentario sobre la financiación de la cultura en el territorio. Ver https:// publications.parliament.uk/pa/cm201617/cmselect/cmcumeds/114/114.pdf

(consultado el 04-09-18). El último Libro Blanco de la Cultura (2016) puede consultarse aquí: https://assets.publishing.service.gov.uk/government/uploads/system/uploads / attachment_data/file/510798/DCMS_The_Culture_White_Paper_3_.pdf (consultado el 21-09-18)

(15) Puede consultarse el listado de las Organizaciones públicas no ministeriales en: https://en.wikipedia.org/wiki/ Non-departmental_public_body (consultado el 04-09-18)

(16) Puede consultarse el listado de los Departamentos de Gobierno no ministeriales en: https://en.wikipedia. org/wiki/Non-ministerial_government_department (consultado el 04-09-18).

(17) Puede consultarse el listado de las Agencias Ejecutivas en: https://en.wikipedia.org/wiki/Executive_agency\#Executive_agency_4 (consultado el 04-09-18).

(18) Puede consultarse el informe de GPS «Rebalancing our Cultural Capital» en este enlace: https://www. artsprofessional.co.uk/sites/artsprofessional.co.uk/files/rebalancing_our_cultural_capital.pdf

(19) Consulta de «A policy for the Arts and Culture in England. The Next Steps», aquí: http://www.gpsculture. co.uk/downloads/next-steps/GPS_Culture-Next_Steps.pdf (consultado el 04-09-18).
(20) Un sistema de financiación, gestionado por una empresa, cuyos resultados flaquean, con la consiguiente preocupación del sector. Ver el informe de Auditoría del último año aquí: https://www.nao.org.uk/wp-content/ uploads / 2017 /12/Investigation-National-Lottery-funding-for-good-causes-.pdf (consultado el 16-10-18).

(21) https://assets.publishing.service.gov.uk/government/uploads/system/uploads/attachment_data/ file/510798/DCMS_The_Culture_White_Paper_3_.pdf

(22) Las opiniones de Kureishi y de un amplio grupo de artistas y críticos, dos décadas después de su gobierno, pueden verse aquí: https://www.theguardian.com/ books/2009/apr/11/thatcher-and-the-arts (consultado el 02-09-18).

(23) Sobre Geoff Mulgan, ver: https://media.nesta. org.uk/documents/geoff_mulgan_-_ideas.pdf_(consultado el 12-10-18).

(24) Sobre Ken Worpole, consultar: http://www.worpole.net $/$ (consultado el 12-10-18).

(25) https://www.artsprofessional.co.uk/news/bath-council-close-arts-development-service

(26) https://es.wikipedia.org/wiki/Richard_Hoggart

(27) https://es.wikipedia.org/wiki/E._P._Thompson

(28) Por señalar el último divulgado, ver este informe https://unctad.org/en/PublicationsLibrary/webditcted2016d5_en.pdf (consultado el 12-10-18).

(29) http://www.oecd.org/cfe/leed/Fulfilling-the-potential-for-CGI-project-description.pdf (consultado el 12-10-18).

(30) Ver el documento: http://ccilc.pt/wpcontent/ uploads/2017/07/eu_sme_centre_report_culture_and_ creative_industries_in_china_jul_2014.pdf (consultado el 12-10-18).

(31) El Informe sobre las Industrias Creativas de Sir Peter Bazalguette (sept. 2017) puede consultarse aquí: https://www.creativeindustriesfederation.com/sites/default/ files/2017-10/Baz\%20review.pdf (consultado el 04-10-18).

(32) http://www.creativepeopleplaces.org.uk/ (consultado el 14-10-2018).

(33) http://jubileeartsarchive.com/wp-content/ uploads / 2015/03/In-Search-of-Cultural-Democracy.pdf (consultado el 12-09-18).

\section{Bibliografía}

AHEARNE, J. (2009). «Cultural Policy Implicit and Explicit: A Distinction and Some Uses». International fournal of Cultural Policy, 15, pp. 141-153. 
BAKHSHI, H. and CUNNINGHAM, S. (2016). "Cultural Policy in the time of the Creative Industries». NESTA. https://media.nesta.org.uk/documents/cultural_ policy_in_the_time_of_the_creative_industries_.pdf

BARKER, A. (ed.) (1982). Quangos in Britain. Government and the Networks of Public Policy-Making, London Basingstoke, Macmillan.

BAZZALGUETTE, P. (2017). «Independent Review of the Creative Industries». DCMS https://www.gov.uk/ government/publications/independent-review-of-the-creative-industries

BECKER, H. (2008). Art Worlds, Berkeley, University of California Press.

BELFIORE, E. (2010). «On bullshit in cultural policy practice \& research». Variant 37, pp. 6-10.

BELFIORE, E., BENNET, O. (2010). The Social Impact of the Arts, London, Palgrave Macmillan.

BELFIORE, E., HADLEY, S. (2018). «Cultural Democracy and Cultural Policy». Cultural Trends 27, n ${ }^{\circ}$ 3, pp. 218-223.

BELL, D., OAKLEY, K. (2014). Cultural Policy, London, Routledge.

BIANCHINI, F. (1983). Urban cultural policy in Britain and Europe: Towards cultural planning, Institute for Cultural Policy Studies, Griffith University.

CAVES, R. (2000). Creative industries. Contracts between art and commerce, Harvard University Press.

GEVASCO, M. E. (2013). Diez lecciones sobre estudios culturales, Buenos Aires, Trilce.

CLARKE, J., GRITCHER, G., and JOHNSON, R., (eds.) (s.d.). Working Class Culture: History and Theory, London, Hutchinson.

DWORKIN, D. (1997). Cultural Marxism in Postwar Britain: History, the New Left, and the Origins of Cultural Studies, Durham N.C., Duke University Press.

FLEW, T. (2012). Creative industries. Culture and Policy, Queensand, Queensand University of Technology.

FROW, J. (1995). Cultural Studies and Cultural Value, London, Glarendon Press.

GPS. (2016). «A Policy for the Arts and Culture in England. The Next Steps?» Documento online: http://www. gpsculture.co.uk/downloads/next-steps/GPS_Culture-Next_Steps.pdf

GRAY, G. (2000), The Politics of the Arts in Britain, Basingstoke, Macmillan.

GRAY, G. (2010). «Analysing Cultural Policy: Incorrigibly Plural or Ontologically Incompatible?». International Journal of Cultural Policy 16, pp. 215-230.
GRAY, C. (2012). «The Structure of Cultural Policy» (Paper presentado en la Conferencia Internacional de Investigación del Políticas Culturales en la Universidad Ramón Llull, Barcelona). http://www2.warwick.ac.uk/fac/arts/ theatre_s/cp/staff/gray/research/

HALL, S. (1992). «Cultural Studies and its Theoretical Legacy» en L. Grossberg, C. Nelson and P. Treichler (eds.), Cultural Studies, New York-London, Routledge, pp. 277294.

HEATHERLEY, O. (2011). A Guide to the New Ruins of Great Britain, London, Verso.

HEBDIGE, D. (1979). Subculture: The meaning of Style, London, Routledge.

HEDMONDSHALGH, D., OAKLEY, K., LEE, D., NISBETT, M., (2014). «Were New Labour's cultural policies neo-liberal?». International fournal of Cultural Policy 21:1, pp. 97-114.

HEDMONDSHALGH, D., OAKLEY, K., LEE, D., NISBETT, M. (2015). Culture, Economy and Politics: The case of the New Labour, London, Pargrave Mcmillan.

HEWISON, R. (1977). Under Siege: Literary life in London 1939-1945, Oxford, Oxford University Press.

HEWISON, R. (1981). In Anger: British Culture in the Cold War (1945-1960), Oxford, Oxford University Press.

HEWISON, R. (1987). Too much: Art and Society in the Sixties (1960-1975), Oxford, Oxford University Press.

HEWISON, R. (1989). The Heritage Industry, London, Methuen.

HEWISON, R. (1995). Culture \& Consensus: England Art and Politics since 1940, London, Methuen.

HEWISON, R. (2014). Cultural Capital: The rise and fall of Creative Britain, London, Verso.

HILLMAN-GHARTRAND, H., McGAUGHEY, C. (1989). «The Arm's-Length Principle and the Arts: An International Perspective» en M. Cummings and M. Schuster (eds.), Who is to Pay?: The International search for Models of Support for the Arts, New York, American Council for the Arts, pp. 43-77.

HOGGART, R. (1957). The Uses of Literacy, London, Chatto \& Windus.

HOWLETT, M. (2011) "Designing Public Policies: Principles and Instruments", London, Routledge.

JEFFERS, A., MORIARTY, G., (2017). Culture, Democracy and the Right to make Art, London, Methuen.

JESSOP, B., BONNET, K., BROMLEY, S., LING, T. (1988). Thatcherism: A Tale of Two Nations, Cambridge, Polity.

KAYE, H. (1995). The British Marxist Historians, London, Palgrave Macmillan. 
KEA European Affairs (2006). The Economy of Culture in Europe. Study for the DG for Education and Culture. http://www. keanet.eu/ecoculture/studynew.pdf? $4 \mathrm{f} 4 \mathrm{eb} 7$

KEA European Affairs (2009). The Impact of Culture on Creativity. Study for the DG for Education and Culture. http://www. keanet.eu/docs/impactculturecreativityfull.pdf

KEA European Affairs (2017). Mapping the Creative value Chains. Study for the DG for Education and Culture. http:// www.keanet.eu/wp-content/uploads/Final-report-Creative-Value-Chains.pdf

KELLY, O. (1986). Culture and Democracy. The Manifesto, London, Comedia.

LEYS, G. (1989). Politics in Britain: From Labourism to Thatcherism, London, Verso.

LLOYD, D. and THOMAS, P. (1998). Culture and the State, London, Routledge.

MATARASSO, F. (1987). Use or Ornament? The Social Impact of Participation in the Arts", London, Comedia. Disponible en http://www.artshealthresources.org.uk/wp-content/ uploads/2017/01/1997-Matarasso-Use-or-Ornament-TheSocial-Impact-of-Participation-in-the-Arts-1.pdf

MIRZA, M., (2012). The Politics of Culture. The Case for Universalism, London, Palgrave Macmillan.

McGUIGAN, J. (1996). Culture and the Public Sphere, London, Routledge.

McROBBIE, A. (1991). Feminism and youth culture, London, Palgrave Mcmillan.

MULCAHY, K. (2017). Public Culture, Cultural Identity, Cultural Policy. Comparative perspectives, London, Palgrave Mcmillan.

MULGAN, G. and WORPOLE, K. (1986). Saturday night or Sunday morning? From Arts to Industry- New forms of Cultural Politics, London, Comedia.

RAUNIG, G. (2007). «La industria creativa como engaño de masas» en Producción cultural y prácticas instituyentes, Madrid, Traficantes de Sueños, pp. 27-42.

SINCLAIR, A. (1995). Arts and Cultures, The History of the 50 Years of the Arts Council of Great Britain, Sinclair-Stevenson.

SCHLESINGER, P. (2009). "Creativity and the Experts. New Labour, Think Tanks and the Policy Process». The International fournal of Press/Politics, 14 (3) pp. 3-20. Disponible en: http://eprints.gla.ac.uk/4895/1/4895.pdf
SCHLESINGER, P. (2016). «The creative economy: Invention of a global orthodoxy». Innovation. The European Journal of Social Science Research, London, Routledge, Taylor and Francis Group.

SRNICEK, N. (2016). Platform Capitalism, London, Wiley.

STOTHARD, P. (2016). The Senecans. Four men and Margaret Thatcher, London, The Overlook Press.

THOMPSON, E.P. (1963). The Making of the English Working Class, London, Victor Gollanzcs.

THROSBY, D. (2010). The Economics of Cultural Policy, Cambridge University Press.

UPGHURGH, A. (2004). «John Maynard Keynes, the Bloomsbury group and the origins of the arts council movement». International fournal of Cultural Policy 10 (2), pp. 203-217.

WILLIAMS, R. (1958). «Culture is ordinary» en R. Williams, Resources of Hope: Culture, Democracy, Socialism, London, Verso, pp. 3-14.

WILLIAMS, R. (1976). Keywords. A Vocabulary of Culture and Society, London, Fontana.

WILLIAMS, R. (1981). Culture, Glasgow, Fontana.

WILLIAMS, R. (1983). Towards 2.000, London, Chatto \& Windus/The Hoggarth Press.

WILLIAMS, R. (1989). «The future of Cultural Studies» en The Politics of Modernism: Against the New Conformists, London, Verso.

WOLFF, J. (1981). The social production of Art, Basingstoke, Macmillan.

Se recomienda la lectura de este artículo junto al publicado en el número 18 de Periférica: view/4182

https://revistas.uca.es/index.php/periferica/article/ 